\title{
Associations with kidney transplant survival and eGFR decline in children and young adults in the United Kingdom: a retrospective cohort study
}

\author{
Alexander J. Hamilton ${ }^{1 *}$ (D) Lucy A. Plumb ${ }^{1,2}$, Anna Casula ${ }^{2}$ and Manish D. Sinha ${ }^{3,4}$
}

\begin{abstract}
Background: Although young adulthood is associated with transplant loss, many studies do not examine eGFR decline. We aimed to establish clinical risk factors to identify where early intervention might prevent subsequent adverse transplant outcomes.

Methods: Retrospective cohort study using UK Renal Registry and UK Transplant Registry data, including patients aged < 30 years transplanted 1998-2014. Associations with death-censored graft failure were investigated with multivariable Cox proportional hazards. Multivariable linear regression was used to establish associations with eGFR slope gradients calculated over the last 5 years of observation per individual.

Results: The cohort ( $n=5121$, of whom $n=371$ received another transplant) was $61 \%$ male, 80\% White and 36\% had structural disease. Live donation occurred in 48\%. There were 1371 graft failures and 145 deaths with a functioning graft over a 39,541-year risk period. Median follow-up was 7 years. Fifteen-year graft survival was $60.2 \%$ (95\% Cl 58.1, 62.3).

Risk associations observed in both graft loss and eGFR decline analyses included female sex, glomerular diseases, Black ethnicity and young adulthood (15-19-year and 20-24-year age groups, compared to 25-29 years). A higher initial eGFR was associated with less risk of graft loss but faster eGFR decline. For each additional $10 \mathrm{~mL} / \mathrm{min} / 1.73 \mathrm{~m}^{2}$ initial eGFR, the hazard ratio for graft loss was 0.82 (95\% Cl 0.79, 0.86), $p<0.0001$. However, compared to $<60 \mathrm{~mL} /$ $\mathrm{min} / 1.73 \mathrm{~m}^{2}$, higher initial eGFR was associated with faster eGFR decline $\left(>90 \mathrm{~mL} / \mathrm{min} / 1.73 \mathrm{~m}^{2} ;-3.55 \mathrm{~mL} / \mathrm{min} /\right.$ $1.73 \mathrm{~m}^{2} /$ year $\left.(95 \% \mathrm{Cl}-4.37,-2.72), p<0.0001\right)$.

Conclusions: In conclusion, young adulthood is a key risk factor for transplant loss and eGFR decline for UK children and young adults. This study has an extended follow-up period and confirms common risk associations for graft loss and eGFR decline, including female sex, Black ethnicity and glomerular diseases. A higher initial eGFR was associated with less risk of graft loss but faster rate of eGFR decline. Identification of children at risk of faster rate of eGFR decline may enable early intervention to prolong graft survival.
\end{abstract}

Keywords: Kidney transplant, Child, Adolescent, Young adult, Graft survival, eGFR

\footnotetext{
* Correspondence: alexander.hamilton@bristol.ac.uk

${ }^{1}$ Population Health Sciences, University of Bristol, G.04, Canynge Hall, 39 Whatley Road, Bristol BS8 2PS, UK

Full list of author information is available at the end of the article
}

(c) The Author(s). 2020 Open Access This article is licensed under a Creative Commons Attribution 4.0 International License, which permits use, sharing, adaptation, distribution and reproduction in any medium or format, as long as you give appropriate credit to the original author(s) and the source, provide a link to the Creative Commons licence, and indicate if changes were made. The images or other third party material in this article are included in the article's Creative Commons. licence, unless indicated otherwise in a credit line to the material. If material is not included in the article's Creative Commons licence and your intended use is not permitted by statutory regulation or exceeds the permitted use, you will need to obtain permission directly from the copyright holder. To view a copy of this licence, visit http://creativecommons.org/licenses/by/4.0/ The Creative Commons Public Domain Dedication waiver (http://creativecommons.org/publicdomain/zero/1.0/) applies to the data made available in this article, unless otherwise stated in a credit line to the data. 


\section{Background}

Kidney transplantation is the optimal treatment for end stage kidney disease (ESKD) in children and young adults as it provides them the best opportunity for normal growth and development, a better quality of life and places fewer restrictions on daily activities [1]. For health service providers, transplantation is also the most costeffective kidney replacement therapy (KRT) modality [2].

Young adulthood though remains a distinct period for risk of graft loss. A large registry study analysing the effect of age identified graft failure rates were highest at 19 years and that those aged 17-24 years were at the highest risk of graft failure [3], with similar findings from other studies not including patients from the UK [4-7]. This may be because both adolescence and young adulthood are associated with increased risk-taking behaviour, poor medication compliance and changes to care as patients transfer to adult services [3, 5]. Furthermore, brain development continues during young adulthood [8], which may impact reasoning and decision-making. Thus, following periods of stable graft function, typically, this may be followed by period of worsening graft function and potential sudden graft failure.

There are few studies including data reporting UK graft survival for children and young adults. These data are though limited for their generalisability as one reported outcomes for transplants between 1973 and 2000 [9] and another described outcomes for deceased donor transplant recipients alone [10]. Two further reports have data on short term outcomes limited to 3-5 years with a specific focus on HLA mismatching: non-inferiority of poorly matched living donor transplants compared to well-matched deceased transplants suggested by one [11], with opposing evidence for this in the larger Collaborative Transplant Study dataset [12]. A recent study reported graft loss outcomes for UK young adults using Hospital Episode Statistics and Office for National Statistics data and showed an increased risk of graft loss relative to other age groups for those aged 14-23 years with 10year follow up [13].

Although it is unlikely that outcomes during adolescence and young adulthood will differ for UK individuals, to our knowledge no studies have evaluated the role of initial transplant function or examine risk factors for declining function. Importantly, studies have been limited in their focus and duration of follow up, with the maximum period of follow up limited to 10 years. This follow-up period is relevant as between 2000 and 2011, UK children received live and donation after brain death kidney transplants at a mean age of $11 \pm 5$ years [11]. The median age at transfer to adult services in the UK is 18 years [14]. Therefore following 10 years of follow up a large proportion would not yet have transferred and many would be under the age of 24 years, reported as the upper limit of the high-risk age window [3].

In this study, we aimed to use explanatory regression models to establish clinical characteristics for early identification of those at risk of declining transplant function and failure using data collected across two major registries that include all children and young adults with follow up data extending beyond childhood and $>10$ years where available. This would allow for the development of targeted interventions intending to preserve transplant function and prevent graft loss. We report graft survival for UK children and young adults and to explore the importance of clinical donor and recipient variables not only for graft loss but also rate of decline, among grafts of varying vintage. To our knowledge, factors associated with graft function decline in children and young adults have not previously been evaluated. Clinical identification of eGFR decline is time-critical for this group and intervention often requires a biopsychosocial approach.

\section{Methods}

We undertook a retrospective cohort study using linked UK Renal Registry (UKRR) and NHS Blood and Transplant (NHSBT) data, including children and young adults aged $<30$ years who underwent kidney transplantation between 1998 and 2014. As UKRR and NHSBT datasets differ, their combination provided comprehensive clinic-demographic data with greater completeness and reliability.

\section{Clinical data from the UKRR and NHSBT}

The UKRR collects data on all patients receiving KRT from UK adult and pediatric kidney units $[15,16]$. It has been granted a section 251 exemption by the Health Research Authority, allowing the registration of identifiable patient information from kidney units without first asking individual patient consent. We defined exposures and covariates in a research protocol and applied for data in October 2017, receiving approval in February 2018. The data was received December 2018-March 2019. The study included all patients aged $<30$ years who received a kidney transplant from 01/01/1998 to $31 / 12 / 2014$. These dates were chosen to reflect full coverage UK kidney units and to ensure at least 1 year of individual follow-up time. Biochemical data was extracted up to the final quarter of 2016. Initial eGFR was calculated from the first biochemical data recorded following transplantation; returns are annual for paediatrics and quarterly for adults. Patients may have previously received a transplant prior to the study period.

NHSBT is a special health authority supporting UK organ transplantation and collects data on transplant outcomes for the UK Transplant Registry (UKTR). 
Informed consent for data collection is obtained from recipients and donor next of kin. We applied for data in November 2017. The data was extracted in October 2018 and included follow-up to this time point, hence was the most recent and used in analyses. NHBT describes human leucocyte antigen (HLA) mismatches according to the UK 2006 National Kidney Allocation scheme, which emphasises DR-locus mismatches to stratify risk [17].

\section{Statistical analyses \\ Graft loss}

We modelled death-censored graft failure over death as a competing risk, as this is felt to be more appropriate for an aetiological research question [18], aiming to identify clinical risk factors. Univariate analyses included Kaplan-Meier survival curves and log-rank tests. We used a conditional risk-set model for multiple failure data [19]. This measures time to event from the time of the previous event, with follow-up time reset to zero after each failure event where patients were retransplanted. So, when retransplanted, the same individual appears twice in the data, as follows:

\begin{tabular}{lllll}
\hline ID & Graft number & Entry time & Exit time & Censored \\
1 & 1 & 0 & 2.17 & 1 \\
1 & 2 & 0 & 13.9 & 0 \\
\hline
\end{tabular}

By using a multivariable Cox proportional hazards model, we explored the association of evidence-based variables as well as initial eGFR post-transplant on the risk of deathcensored graft failure [hazard ratio (HR) (95\% confidence interval (CI)), $p$-value]. We analysed age group as timevarying and used stratification by graft number, clustering at the participant level (to account for some participants appearing more than once in the dataset) and Efron's method for handling ties [20]. We tested for the assumption of proportionality using visual plots, Schoenfeld residuals and testing for a log-time interaction. As some indication of non-proportionality was observed for glomerular diseases versus other kidney diseases, we also performed piecewise Cox regression to confirm the results.

\section{eGFR trend}

We chose to explore eGFR decline assuming linearity given that this is a widely used and well-established method [21-23]. We calculated estimated glomerular filtration rate (eGFR) using the Schwartz formula [24] if aged $<18$ years and the 4 -variable Modification of Diet in Renal Disease formula [25] otherwise. Although it has been suggested to average pediatric and adult serum Creatinine-based eGFR equations for those aged 18-26 years [26], our approach reflects current UK clinical practice. Where height was missing, the previous entry was substituted. Where ethnicity was missing, white ethnicity was substituted. For participants with $\geq 3$ eGFR values outside the first 6 months post-transplant, individual linear regressions (least squares) of eGFR against time were performed using the most recent 5 years of data per participant. For example, for someone transplanted in 2005 with a functioning graft throughout the study period, we used data from 2012 to 2016. Analysis of patient-level eGFR slopes suggested that linear modelling provided a reasonably accurate fit for the timeperiod of kidney function explored. Using the most recent 5 years of observation resulted in greater linearity than using all available data and less combined use of eGFR equations in the same individual. Since eGFR was calculated to create a regression line, the equation used was of less importance as regression line gradients would be similar, and the regression line would smooth any missing eGFR values. For quarterly data, the data collection quarter mid-point was used.

We used backward elimination and examined explanatory variables in univariate models to establish associations with eGFR slope gradients. We combined associated variables $(p<0.05)$ in a multivariable linear (least squares) regression model and removed explanatory variables from the final model if there was no statistical association when co-adjusted, having checked that this did not affect the regression coefficients of the remaining variables. We checked for assumptions of linearity between continuous variables and the outcome variable, evidence of heteroscedasticity and normally distributed residuals with a mean of zero. Where non-linear, continuous variables were categorised into clinically relevant groups. We tested for potential pre-specified interactions: 1) sex and primary kidney disease, 2) initial eGFR and sex, 3) ethnicity and primary kidney disease, 4) initial eGFR and ethnicity (as ethnicity contributes to eGFR equations). Data are reported appropriate to their distribution. We used Stata v.15 for our analyses.

\section{First eGFR post-transplant}

Data returns to the UKRR are annual for paediatric patients and quarterly for adult patients. The first serum creatinine result reported to the UKRR post-transplant for paediatrics is at 3 months (alongside a height measurement) and within the first 3 months for adults. These data were used to derive the first eGFR measurement in the first 3 months following transplantation, thus reflecting early steady state.

\section{Results}

Completeness was high for most items (Table 1). Deaths were discordant between UKRR and UKTR datasets. All 
Table 1 Patient and transplant characteristics

\begin{tabular}{|c|c|c|c|}
\hline Variable & Total $\mathbf{n}$ & $\mathbf{n}$ & $\%$ \\
\hline Male sex & 5121 & 3107 & 60.7 \\
\hline \multicolumn{4}{|l|}{ Ethnic group } \\
\hline White & 4918 & 3955 & 80.4 \\
\hline Asian & & 579 & 11.8 \\
\hline Black & & 215 & 4.4 \\
\hline Mixed/other & & 169 & 3.4 \\
\hline \multicolumn{4}{|l|}{ Primary kidney disease group ${ }^{a}$} \\
\hline Glomerular disease & 5065 & 1467 & 29.0 \\
\hline Systemic diseases affecting the kidney & & 304 & 6.0 \\
\hline Familial/hereditary nephropathies & & 593 & 11.7 \\
\hline Tubulointerstitial disease & & 1808 & 35.7 \\
\hline Miscellaneous kidney disorders & & 893 & 17.6 \\
\hline Late presentation ${ }^{\mathbf{b}}$ & 3366 & 867 & 25.8 \\
\hline Age when first seen (years) (median, IQR) & 3389 & 13.1 & $2.7,20.0$ \\
\hline Age at KRT start (years) (median, IQR) & 5085 & 19.1 & $12.9,24.1$ \\
\hline Years to KRT start from first nephrology review (median, IQR) & 3370 & 2.0 & 0.2 .5 .4 \\
\hline Tertiles of year started KRT (median, IQR) & 5085 & 2006 & 2001, 2009 \\
\hline 1983-2003 & 5085 & 1936 & 38.1 \\
\hline 2004-2008 & & 1607 & 31.6 \\
\hline 2009-2014 & & 1542 & 30.3 \\
\hline \multicolumn{4}{|l|}{ Start modality } \\
\hline Haemodialysis & 5102 & 2011 & 39.4 \\
\hline Peritoneal dialysis & & 1839 & 36.0 \\
\hline Transplant & & 1252 & 24.5 \\
\hline Age at transfer (years) (median, IQR) & 1455 & 18 & $17.4,18.5$ \\
\hline Died & 5121 & 260 & 5.1 \\
\hline Age at death (years) (median, IQR) & 260 & 27.6 & $20.3,32.3$ \\
\hline \multicolumn{4}{|l|}{ Transplanted during study period } \\
\hline Graft 1 & 4750 & 4377 & 85.5 \\
\hline Graft 2 & & 371 & 7.2 \\
\hline Graft 3 & & 2 & 0.04 \\
\hline \multicolumn{4}{|l|}{ Re-transplanted during study period } \\
\hline Graft 2 & 371 & 369 & 7.2 \\
\hline Graft 3 & & 2 & 0.04 \\
\hline Time from listing to transplant (years) (median, IQR) & 4416 & 0.8 & $0.3,1.8$ \\
\hline \multicolumn{4}{|l|}{ Year of transplant } \\
\hline 1998-2003 & 5121 & 1291 & 25.2 \\
\hline 2004-2009 & & 1930 & 37.7 \\
\hline 2010-2014 & & 1900 & 37.1 \\
\hline \multicolumn{4}{|l|}{ Donor type } \\
\hline Live donation & 5121 & 2462 & 48.1 \\
\hline Donation after brainstem death & & 2356 & 46.0 \\
\hline Donation after circulatory death & & 303 & 5.9 \\
\hline Donor age (years) (median, IQR) & 5115 & 41 & 27,49 \\
\hline
\end{tabular}


Table 1 Patient and transplant characteristics (Continued)

\begin{tabular}{|c|c|c|c|}
\hline Variable & Total $n$ & $\mathbf{n}$ & $\%$ \\
\hline Cold ischaemic time (hours) (median, IQR) & 4651 & 9.3 & $2.8,16.3$ \\
\hline Calculated reaction frequency $(\%)\left(\right.$ median, IQR) ${ }^{c}$ & 5118 & 0 & 0,12 \\
\hline \multicolumn{4}{|l|}{ HLA mismatch group ${ }^{d}$} \\
\hline 0 mismatches & 5120 & 544 & 10.6 \\
\hline [0 HLA-DR and 0/1 HLA-B] mismatches & & 2016 & 39.4 \\
\hline [0 HLA-DR and 2 HLA-B] or [1 HLA-DR and 0/1 HLA-B] mismatches & & 2272 & 44.4 \\
\hline [1 HLA-DR and 2 HLA-B] or [2 HLA-DR] mismatches & & 288 & 5.6 \\
\hline First eGFR $\left(\mathrm{mL} / \mathrm{min} / 1.73 \mathrm{~m}^{2}\right)\left(\right.$ mean, SD) ${ }^{\mathrm{e}}$ & 4882 & 62 & 23 \\
\hline Rate of eGFR change (mL/min/1.73m²/year) (mean, SD) & 4487 & -3.14 & 7.69 \\
\hline Graft failure & 5111 & 1376 & 26.9 \\
\hline Follow up time (years) (median, IQR) & 5111 & 7.0 & $4.0,10.9$ \\
\hline Time to event (years) (median, IQR) & 1376 & 4.2 & $1.5,7.6$ \\
\hline Patient death & 4750 & 238 & 5.0 \\
\hline Follow up time (years) (median, IQR) & 4750 & 8.8 & $5.1,13.0$ \\
\hline Time to event (years) (median, IQR) & 238 & 6.6 & $3.0,10.6$ \\
\hline Age at event (mean, SD) & 5111 & 27.5 & 8.7 \\
\hline
\end{tabular}

IQR interquartile range, KRT kidney replacement therapy, SD standard deviation, HLA human leucocyte antigen, eGFR estimated glomerular filtration rate Ages are based on dates of birth rounded to mid-month

a Primary kidney disease was using a 2012 European coding system [27]. The pediatric diagnosis was used where discordant between pediatric and adult databases [28]

${ }^{\mathrm{b}}$ Late presentation defined as $\leq 90$ days from first nephrology review to RRT start

CCalculated reaction frequency is defined as the percentage of ABO-identical patients within the donor pool that are HLA incompatible with an individual patient and is dependent on blood group and antibodies [29]

'HLA mismatch groups were derived from the UK 2006 National Kidney Allocation scheme [17]. The HLA-A:B:DR mismatches included in each group are as follows:

[0 HLA-DR and 0/1 HLA-B] - 1:0:0, 0:1:0, 1:1:0, 2:0:0, 2:1:0

[O HLA-DR and 2 HLA-B] or [1 HLA-DR and 0/1 HLA-B]

$0: 2: 0,1: 2: 0,2: 2: 0,0: 0: 1,1: 0: 1,2: 0: 1,0: 1: 1,1: 1: 1,2: 1: 1$

[1 HLA-DR and 2 HLA-B] or [2 HLA-DR]

$0: 2: 1,1: 2: 1,2: 2: 1,0: 0: 2,1: 0: 2,2: 0: 2,0: 1: 2,1: 1: 2,2: 1: 2,0: 2: 2,1: 2: 2,2: 2: 2$

eGFR post-transplant calculated from the first biochemical data recorded by the UK Renal Registry following transplantation. Returns are annual for paediatrics and quarterly for adults

patients with a coded UKTR death and no UKRR death $(n=32)$ died after the final date in the UKRR data extraction. Almost all the patients with a coded UKRR death and no UKTR death $(n=45)$ died after the followup time for graft and patient outcomes in the UKTR data. The remaining patient $(n=1)$ had biochemical data submitted after the death date and is a likely error. As the UKTR outcome data was used this did not affect the graft loss analysis.

Clinical characteristics are displayed in Table 1, with additional detail in Supplemental Table 1. The cohort $(n=5121)$ mostly included one graft during the study period $(n=4750$, this was predominantly the patient's first ever transplant $(n=4377)$ but it may have been their second $(n=371)$ or third $(n=2)$ kidney). Seven percent $(n=371)$ received an additional transplant during the study period, primarily the patient's second transplant $(n=369)$ with third transplants being uncommon $(n=2)$. The median age at the patient's first transplant was 21 years (interquartile range (IQR) 14, 26). The cohort was $61 \%$ male, $80 \%$ white and $36 \%$ had ESKD due to structural kidney disorders. A quarter started KRT within 90 days of their first nephrology review. Preemptive transplantation occurred in 25\%. Median kidney transplant waitlist time was 0.8 years (IQR 0.3 , 1.8). Participants lived a median of $26.2 \mathrm{~km}$ (IQR 10.7, 54.8) from their transplant centre. Live donation occurred in $48 \%$. Median cold ischaemic time was $9.3 \mathrm{~h}$ (IQR 2.8, 16.3). HLA matching was considered 'good' (either no mismatches or 0 HLA-DR and 0/1 HLA-B mismatch) in 50\% [17]. Mean first eGFR was $62 \mathrm{~mL} /$ $\min / 1.73 \mathrm{~m}^{2}$ (see Table 1 footnote), with a mean linear change of $-3 \mathrm{~mL} / \mathrm{min} / 1.73 \mathrm{~m}^{2} /$ year over the most recent five years of follow-up.

There were 1371 graft failures and 145 deaths with a functioning graft over a 39,541-year risk period. Median follow-up was 7 years. Graft survival was as follows: 1year 94.4\% (95\% CI 93.7, 95.0), 5-year 84.0\% (95\% CI $82.9,85.0$ ), 10-year $71.1 \%$ (95\% CI 69.6, 72.5), 15-year $60.2 \%(95 \%$ CI 58.1, 62.3) and 20-year 51.2\% (95\% CI $47.6,54.7 \%)$. Graft survival varied by age at transplant 
and changed over time (Fig. 1); although those transplanted aged 0-4 years had the least initial graft survival, by 10 years they had the highest graft survival. Those transplanted aged 15-19years had the fastest rate of transplant failure. At 15 years, those transplanted aged $0-4$ years had a survivor function of $71.7 \%$ (95\% CI 63.4, $78.5)$ compared to $54.4 \%(95 \%$ CI $49.9,58.7)$ for those transplanted aged $15-19$ years, $p<0.0001$.

Associations with graft loss from the multivariable Cox proportional hazards model are shown in Table 2 and visually in Fig. 2. Graft loss varied over the age spectrum; compared to 25-29 years, being aged 5-9 years was a protective association (HR 0.49 (95\% CI $0.33,0.73), p<0.0001)$, whereas young adulthood was a risk association (15-19 years, HR 1.54 (95\% CI 1.29 , 1.83), $p<0.0001$; 20-24 years, HR 1.41 (95\% CI 1.20 , 1.67), $p<0.0001)$. Older age was associated with reduced risk of graft loss (30-34 years, HR 0.75 (95\% CI $0.60,0.94), p=0.01)$. Other protective associations were having a live donor (HR 0.86 (95\% CI 0.76, 0.97), $p=$ 0.01 ) and higher initial eGFR (per $10 \mathrm{~mL} / \mathrm{min} / 1.73 \mathrm{~m}^{2}$ ) (HR $0.82 \quad(95 \%$ CI $0.79, \quad 0.86), p<0.0001)$. Risk associations included female sex (HR 1.13 (95\% CI 1.00, 1.28), $p=0.049$, adverse HLA mismatches (HR 1.50 (95\% CI 1.19, 1.89), $p=0.001)$, Black ethnicity (HR 1.51 (95\% CI 1.15, 1.97), $p=0.003$ ), and glomerular diseases (HR 1.30 (95\% CI 1.14, 1.48), $p<0.0001$ ). We found no statistical relationship with time period, calculated reaction frequency, socio-economic status or preemptive transplantation in multivariable analyses.
Univariable hazard ratios are shown in Supplemental Table 2. A piecewise model split at one year is shown in Supplemental Table 3.

Associations with eGFR decline are shown in Table 3 and visually in Fig. 3. Regression coefficients represent rate of annual eGFR change $\left(\mathrm{mL} / \mathrm{min} / 1.73 \mathrm{~m}^{2} /\right.$ year$)$. Risk associations for eGFR decline included female sex $\left(-0.89 \mathrm{~mL} / \mathrm{min} / 1.73 \mathrm{~m}^{2} /\right.$ year $(95 \%$ CI $-1.36,-0.42), p<$ $0.0001)$, glomerular diseases $\left(-0.95 \mathrm{~mL} / \mathrm{min} / 1.73 \mathrm{~m}^{2} /\right.$ year (95\% CI -1.47, - 0.44), $p<0.0001)$, young adulthood, Black ethnicity and higher initial transplant function. Compared to being aged 25-29 years, being aged 15-24 years was associated with eGFR decline (15-19 years, $\quad-1.27 \mathrm{~mL} / \mathrm{min} / 1.73 \mathrm{~m}^{2} /$ year $\quad(95 \% \quad \mathrm{CI}$ $-1.99,-0.54), p=0.001 ; 20-24$ years, $-1.45 \mathrm{~mL} / \mathrm{min} /$ $1.73 \mathrm{~m}^{2} /$ year $(95 \%$ CI $\left.-2.11, \quad-0.80), p<0.0001\right)$. Compared to White, Black ethnicity was associated with eGFR decline $\left(-1.52 \mathrm{~mL} / \mathrm{min} / 1.73 \mathrm{~m}^{2} /\right.$ year $(95 \%$ CI $-2.67,-0.38), p=0.009)$. Compared to an initial eGFR of $<60 \mathrm{~mL} / \mathrm{min} / 1.73 \mathrm{~m}^{2}$, higher initial eGFR was associated with eGFR decline $\left(60-90 \mathrm{~mL} / \mathrm{min} / 1.73 \mathrm{~m}^{2}\right.$, - $0.56 \mathrm{~mL} / \mathrm{min} / 1.73 \mathrm{~m}^{2} /$ year $(95 \% \mathrm{CI}-1.05,-0.07), p=$ $0.03) ;>90 \mathrm{~mL} / \mathrm{min} / 1.73 \mathrm{~m}^{2},-3.55 \mathrm{~mL} / \mathrm{min} / 1.73 \mathrm{~m}^{2} /$ year (95\% CI -4.37, - 2.72), $p<0.0001)$. A significant interaction $(p<0.0001)$ was found between ethnicity and initial eGFR, with stratum-specific exposure effects detailed in Table 3 . The most clinically relevant was for Black ethnicity and initial eGFR $>90 \mathrm{~mL} / \mathrm{min} / 1.73 \mathrm{~m}^{2}$, associated with an eGFR decline of $-9.00 \mathrm{~mL} / \mathrm{min} / 1.73$ $\mathrm{m}^{2} /$ year (95\% CI $\left.-12.6,-5.44\right) ; p<0.0001$. Conversely,

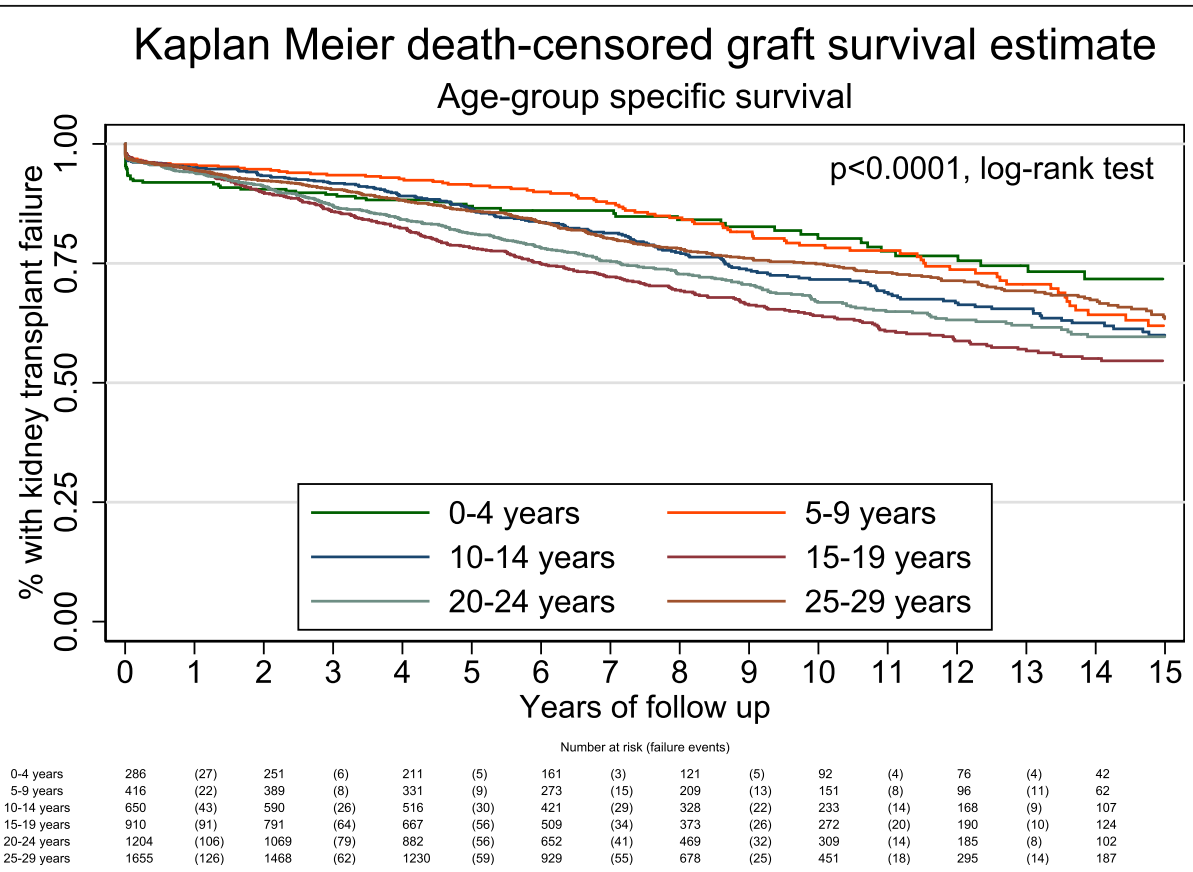

Fig. 1 The youngest age group had the highest initial kidney transplant failure rate but the best long-term transplant survival. Young adults (aged 15-24 years) had the poorest long-term transplant survival 
Table 2 Multivariable Cox proportional hazards examining associations with death-censored kidney transplant failure in UK patients transplanted under 30 years of age

\begin{tabular}{|c|c|c|c|c|}
\hline \multirow[t]{2}{*}{ Variable } & \multirow{2}{*}{$\begin{array}{l}\text { Hazard } \\
\text { Ratio }\end{array}$} & \multicolumn{2}{|c|}{ 95\% confidence interval } & \multirow[t]{2}{*}{$p$-value } \\
\hline & & Lower & Upper & \\
\hline Female sex & 1.13 & 1.00 & 1.28 & 0.049 \\
\hline Live donor (cf. deceased donor) & 0.86 & 0.76 & 0.97 & 0.01 \\
\hline $\begin{array}{l}\text { Human Leucocyte Antigen mismatches }{ }^{\mathrm{a}} \\
\text { [One DR \& two B locus OR two DR locus mismatches] }\end{array}$ & 1.50 & 1.19 & 1.89 & 0.001 \\
\hline $\begin{array}{l}\text { Higher first reported eGFR post-transplant }{ }^{\mathbf{b}} \\
\left(\text { per } 10 \mathrm{~mL} / \mathrm{min} / 1.73 \mathrm{~m}^{2}\right)\end{array}$ & 0.82 & 0.79 & 0.86 & $<0.0001$ \\
\hline Glomerular diseases ${ }^{c, d}$ & 1.30 & 1.14 & 1.48 & $<0.0001$ \\
\hline \multicolumn{5}{|l|}{ Age group (cf. 25-29 years) } \\
\hline $2-4$ & 0.73 & 0.44 & 1.23 & 0.2 \\
\hline $5-9$ & 0.49 & 0.33 & 0.73 & $<0.0001$ \\
\hline $10-14$ & 0.93 & 0.73 & 1.17 & 0.5 \\
\hline $15-19$ & 1.54 & 1.29 & 1.83 & $<0.0001$ \\
\hline $20-24$ & 1.41 & 1.20 & 1.67 & $<0.0001$ \\
\hline $30-34$ & 0.75 & 0.60 & 0.94 & 0.01 \\
\hline $35-39$ & 0.78 & 0.54 & 1.11 & 0.2 \\
\hline $40-44$ & 0.82 & 0.39 & 1.70 & 0.6 \\
\hline \multicolumn{5}{|l|}{ Ethnicity (compared to White) } \\
\hline Asian & 1.02 & 0.83 & 1.24 & 0.9 \\
\hline Black & 1.51 & 1.15 & 1.97 & 0.003 \\
\hline Mixed/Other & 1.02 & 0.71 & 1.44 & 0.9 \\
\hline \multicolumn{5}{|l|}{ Year of transplant (cf. 1998-2005) } \\
\hline $2006-2010$ & 1.05 & 0.91 & 1.21 & 0.5 \\
\hline $2011-2014$ & 1.17 & 0.97 & 1.42 & 0.1 \\
\hline
\end{tabular}

Stratified by transplant number in the study period. Standard error adjusted for 4392 clusters

Live donation by ethnic group was as follows: White, 49\%; Asian, 32\%, Black, 37\%; Mixed/Other, $48 \%$

aHLA mismatch groups were derived from the UK 2006 National Kidney Allocation scheme [17]

beGFR post-transplant calculated from the first biochemical data recorded by the UK Renal Registry following transplantation. Returns are annual for paediatrics and quarterly for adults

'Primary kidney disease was using a 2012 European coding system [27]. The pediatric diagnosis was used where discordant between pediatric and adult databases [28]

${ }^{d}$ There was non-proportionality over time between those with and without glomerular diseases. Piecewise Cox regression analyses split at 1 year showed similar effects for glomerular diseases [ $\leq 1$ year HR $2.05(1.34,3.14), p=0.001$; > 1 year HR $1.24(1.08,1.43), p=0.002)$ and no effect on other HRs; this model presents the overall HR for the entire follow-up period

'The 45-49-year age group is suppressed due to small numbers $(n=8)$

there was no statistical difference in rate of eGFR decline for other ethnic groups across initial eGFR groups. There were no interactions between sex and primary kidney disease, sex and initial eGFR or ethnicity and primary kidney disease. Univariable coefficients are shown in Supplemental Table 4.

\section{Discussion}

This study reports long-term graft survival for UK children and young adults and evaluates associations with both transplant failure and eGFR decline. This study provides an extended follow-up period relative to the established literature using high-quality linked datasets; this was necessary to develop a complete dataset of biochemical data and transplant outcomes and enabled comprehensive analysis of relevant clinical variables. In addition to being a risk factor for graft loss, it highlights that young adulthood is associated with eGFR decline in individuals transplanted before the age of 30 years. Risk associations for both outcomes included female sex, young adulthood (15-24 years), glomerular diseases and Black ethnicity. Initial transplant function was bidirectionally associated with both outcomes, with better initial function being associated with less risk of graft loss but a faster rate of eGFR decline. There are scarce data on eGFR decline among children and young adults, yet graft health is considered a core outcome for research [30]. Whilst it might be assumed that risk factors may be similar for eGFR decline and graft loss, this can now be confirmed. 


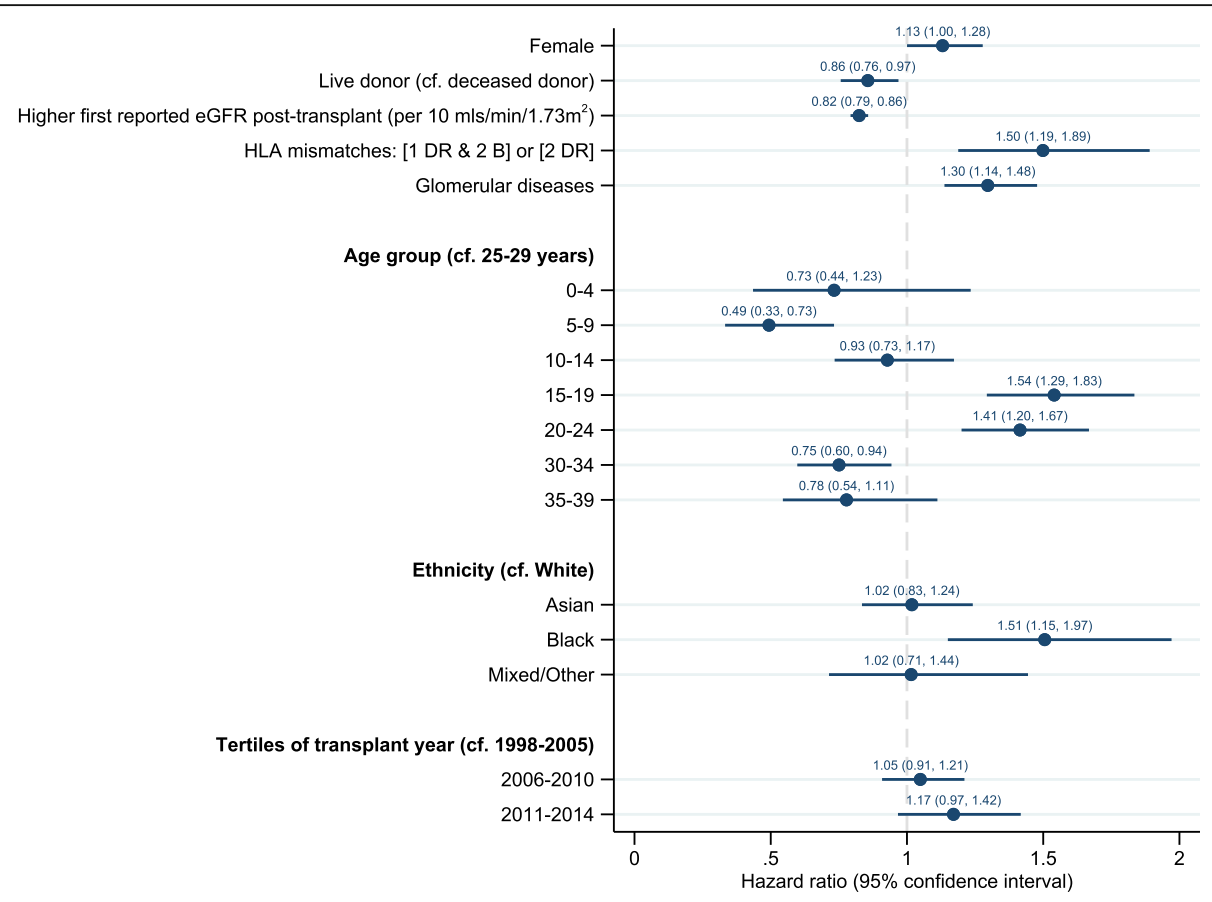

Fig. 2 An increased hazard ratio of death-censored kidney transplant failure was associated with female sex, deceased kidney donation, lower initial kidney transplant function, more HLA mismatches, young adulthood (age group 15-24), Black ethnicity and glomerular diseases. N=4392. eGFR, estimated glomerular filtration rate; HLA, human leucocyte antigen

This study confirms the association between young adulthood and graft loss for UK patients. Compared to $25-29$ years, being aged $15-24$ years is associated with faster eGFR decline, but children reaching this age have a higher risk of graft loss, irrespective of time from transplant. Most UK patients transfer to adult centres at 18 years, suggesting age-related risks are not solely about transition of care and interventions may be required across pediatric and adult services. Young adults on KRT need psychosocial support. Compared to the general population, they have impaired relationships, independence, employment, quality of life, mental wellbeing and psychological health [31, 32]. Low medication adherence is common, affecting 43\% [33]. Young adults live with uncertainty, thwarted ambitions, body image issues and social isolation [34]. Healthcare services for young people vary internationally, with different UK models proposed [35, 36]. However, UK psychologists and social worker provision falls short of workforce recommendations [37, 38].

High rates of graft loss for young patients have been reported, but with limited follow-up [3]. Fiveyear European graft survival for children has been reported at 88\% [39]. Our extended follow-up period enabled observation of better 10-year graft survival for children aged 0-4years relative to other age groups, despite an early increased risk of failure. Younger patients are more likely to have a live donor
(55\% of the $0-4$ year age group, compared to $48 \%$ of the 25-29 year age group, $p=0.04$ ) or a deceased transplant from a younger donor (median donor age in the $0-4$ year age group was 23 years (IQR 23, 41) compared to 39 years (IQR 24, 50) in the 25-29 year age group, $p<0.0001)$. These factors are associated with a lower risk of graft loss [5, 40, 41]. As would be expected, young children aged 5-9 were low risk for death-censored kidney transplant loss. In these young children medications will be administered by parents and compliance less likely to be of concern. Young age may confer an immunological advantage, with a relatively naïve adaptive immunity more capable of accommodating the foreign graft [42].

Our findings confirm the association of female sex, Black ethnicity and glomerular diseases with graft loss $[3,5]$. Black ethnicity is associated with poor graft outcomes in UK adults, although this may be mediated by reduced access to live donors and HLA mismatching, perhaps due to inherent biological ethnic differences [43]. Our study categorised HLA group emphasising HLA-DR locus mismatches to stratify risk, contrasting with non-UK studies which tend to report total mismatches. Using this classification, we found that adverse mismatches were associated with graft loss but not with eGFR decline, possibly due to the rarity of adverse mismatches (6\%). Whilst shown to be associated with graft loss in adult populations $[44,45]$, few studies report the 
Table 3 Multivariable linear regression examining associations with eGFR decline in UK patients transplanted under 30 years of age

\begin{tabular}{|c|c|c|c|c|}
\hline \multirow[t]{2}{*}{ Variable } & \multirow[t]{2}{*}{ Coefficient } & \multicolumn{2}{|c|}{$95 \%$ confidence interval } & \multirow[t]{2}{*}{$p$-value } \\
\hline & & Lower & Upper & \\
\hline Female sex & -0.89 & -1.36 & -0.42 & $<0.0001$ \\
\hline Glomerular diseases $^{a}$ & -0.95 & -1.47 & -0.44 & $<0.0001$ \\
\hline \multicolumn{5}{|l|}{ Ethnicity (cf. White) } \\
\hline Asian & 0.41 & -0.31 & 1.14 & 0.3 \\
\hline Black & -1.52 & -2.67 & -0.38 & 0.009 \\
\hline Mixed/Other & 0.42 & -0.88 & 1.71 & 0.5 \\
\hline \multicolumn{5}{|c|}{ First reported eGFR post-transplant ${ }^{\mathrm{b}}$ (cf. $<60 \mathrm{~mL} / \mathrm{min} / 1.73 \mathrm{~m}^{2}$ ) } \\
\hline $60-90$ & -0.56 & -1.05 & -0.07 & 0.03 \\
\hline$>90$ & -3.55 & -4.37 & -2.72 & $<0.0001$ \\
\hline \multicolumn{5}{|c|}{ Age group ${ }^{c}$ (cf. 25-29 years) } \\
\hline $2-4$ & -1.73 & -3.47 & 0.01 & 0.05 \\
\hline $5-9$ & -0.07 & -1.16 & 1.01 & 0.9 \\
\hline $10-14$ & -0.23 & -1.12 & 0.66 & 0.6 \\
\hline $15-19$ & -1.27 & -1.99 & -0.54 & 0.001 \\
\hline $20-24$ & -1.45 & -2.11 & -0.80 & $<0.0001$ \\
\hline $30-34$ & 0.70 & -0.07 & 1.47 & 0.08 \\
\hline $35-39$ & 1.18 & -0.04 & 2.40 & 0.06 \\
\hline $40-44$ & 2.07 & -0.54 & 4.67 & 0.1 \\
\hline
\end{tabular}

aprimary kidney disease was using a 2012 European coding system [52]. The pediatric diagnosis was used where discordant between pediatric and adult databases [28]

${ }^{b}$ eGFR post-transplant calculated from the first biochemical data recorded by the UK Renal Registry following transplantation. Returns are annual for paediatrics and quarterly for adults. There was evidence of non-linearity between initial eGFR and eGFR decline and therefore data are presented as categorical

${ }^{\mathrm{C}}$ Age at start of eGFR slope analysis. Age range grouped into 5 -year bands, however there were no transplants under the age of 2 years

The regression coefficient of the model intercept was $-1.54(95 \% \mathrm{Cl},-2.08$ to $-1.00 ; p<0.0001)$

There were no interactions between: sex and primary kidney disease, sex and initial eGFR or primary kidney disease and ethnicity. There was a significant interaction (likelihood ratio test $p<0.0001$ between full model and model fitting the interaction term) between initial eGFR and ethnicity. The stratum-specific exposure effects of initial eGFR and ethnicity (compared with White, eGFR $<60 \mathrm{~mL} / \mathrm{min} / 1.73 \mathrm{~m}^{2}$ ) are as follows:

Asian, eGFR 60-90 $0.11(95 \% \mathrm{Cl}-1.45,1.66), p=0.9$

Asian, eGFR > $90-0.49(95 \% \mathrm{Cl}-2.73,1.76), p=0.7$

Black, eGFR 60-90 $0.30(95 \% \mathrm{Cl}-2.17,2.77), p=0.8$

Black, eGFR > $90-9.00(95 \% \mathrm{Cl}-12.6,-5.44), p<0.0001$

Mixed/Other, eGFR 60-90 $-0.34(95 \% \mathrm{Cl}-3.08,2.40), p=0.8$

Mixed/Other, eGFR $>90-2.25(95 \% \mathrm{Cl}-6.55,2.05), p=0.3$

impact of initial transplant function in children and young adults. One study reported graft survival benefits with an eGFR $\geq 30 \mathrm{~mL} / \mathrm{min} / 1.73 \mathrm{~m}^{2}$ at 6 months posttransplant, among other factors [46]. Higher initial eGFR appears protective for graft loss within this population, independent of HLA mismatching and living donation. This indicates benefit from good-quality organs and the need to minimise established factors (e.g. cold ischemic time) known to negatively impact graft survival.

In the UK, a return to dialysis is estimated to cost an additional $£ 10,000$ per year, however failing grafts may lead to the need for increased appointments and psychological support, ongoing immunosuppression, management of anaemia and metabolic bone disease, dialysis planning and transplant nephrectomy [47, 48], as well as frailty, incurring higher costs. In this study, we also sought to determine factors predictive of eGFR decline. Contrary to graft loss, which is a late and less frequent outcome, rate of graft decline is a 'real-time' measure often used by clinicians and families to gauge graft health post-transplant. Although the risk factors identified are inherently non-modifiable, they can 1) help clinicians to identify patients who may benefit from enhanced care and 2) help patients to understand and manage expectations of their transplant function. Future work could include the derivation and validation of a prognostic tool to allow patients and clinicians to personalise post-transplant care and alternative approaches to modelling longitudinal transplant function.

Understanding risk associations for graft loss and decline could help early identification of patients for close monitoring, psychosocial support and targeted intervention. Interventions to structure medicationtaking are needed, since adherence is worse on the weekend [49]. Among young adults, information technology-based interventions show promise in 


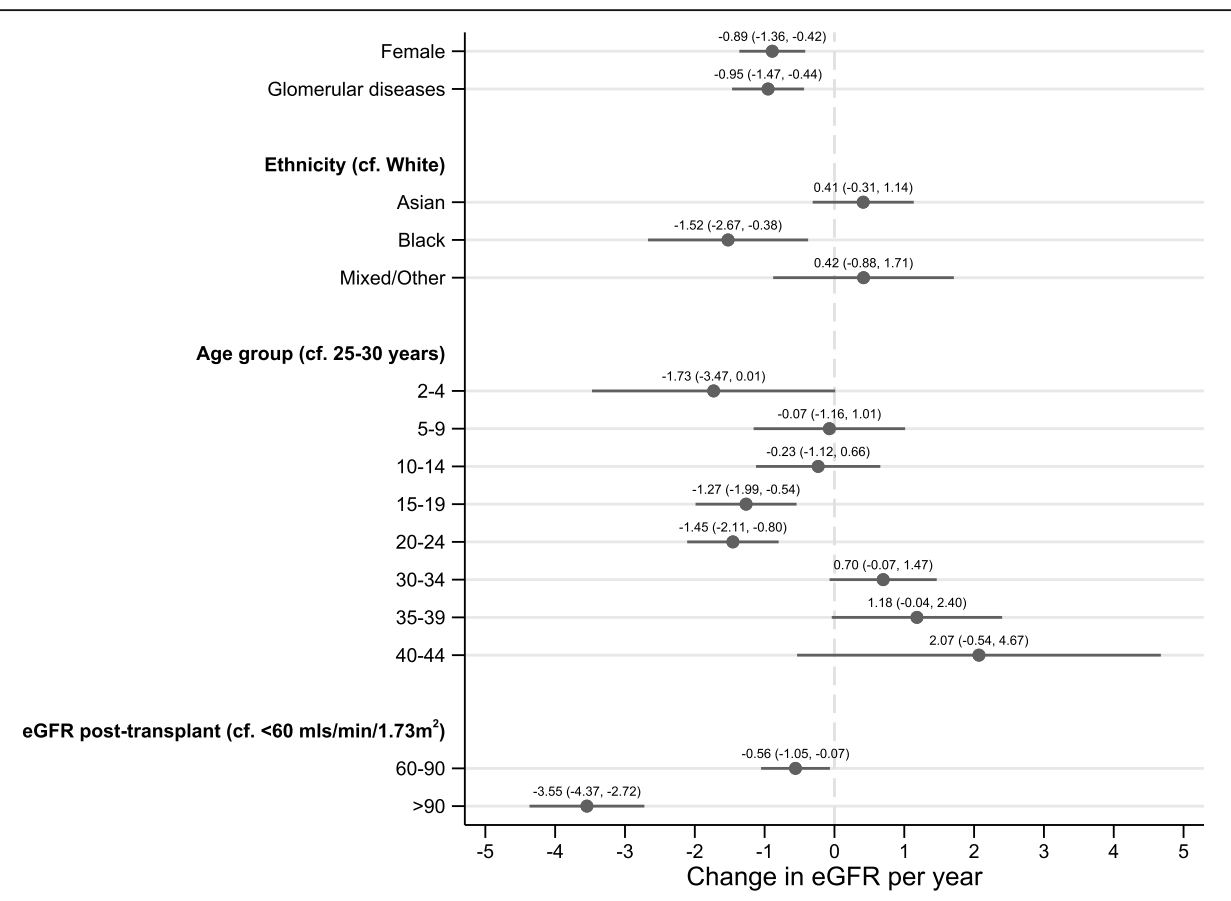

Fig. 3 eGFR decline was associated with female sex, glomerular diseases, Black ethnicity, young adulthood (age group 15-24) and higher initial kidney transplant function. $N=4284$. The regression coefficient of the model intercept was $-1.54(95 \% \mathrm{Cl},-2.08$ to $-1.00 ; p<0.0001)$. The model $R^{2}$ was 0.04 . eGFR, estimated glomerular filtration rate

improving care process self-management outcomes, but their effect on clinical outcomes is less certain [50]. Furthermore, developmentally appropriate interventions will need to be considered for this age-range. Worse outcomes for medication adherence are associated with mental health problems [33]. For UK patients with depression and a chronic physical health problem, National Institute for Health and Clinical Excellence (NICE) recommendations include individual guided self-help through cognitive behavioural therapy [51]. In the lowintensity Improving Access to Psychological Therapies (IAPT) service, a Psychological Wellbeing Practitioner supports patients with frequent but brief coaching [52]. IAPT is effective; depression and anxiety screening scale scores fell with treatment, leading to recovery in $\sim 55 \%$ of cases. A 5\% improvement in employment was observed, associated with lower unemployment benefit costs and higher taxes from employment [53]. Studies evaluating the role of psychological therapies in young adults with transplants are needed.

This is the first UK study to explore risk factors for graft loss as well as eGFR decline for children and young adults. The use of high-quality datasets enabled a long follow-up period, high data completeness and the evaluation of relevant clinic-demographic covariates (excluding immunosuppression regimes). We included second and third grafts in our analyses, which affected $15 \%$ of patients. Their inclusion ensures our study population is representative of the child and young adult KRT population in the UK and findings therefore reflect 'real-world' data relevant to patients seen in everyday clinical practice. Differing coding systems may limit international comparisons. In our Cox model, there was nonproportionality over time between by kidney disease group, although similar effects were seen in a piecewise model. eGFR decline was modelled over the most recent 5 years of data per patient, assuming linearity. This may not capture the effect of factors associated with initial eGFR decline and may explain why some factors are not common to both analyses, such as HLA mismatch and donor type. Newer alternative techniques, including Bayesian smoothing, allow analysis of all available eGFR data, which may be more representative [54]. We substituted the previous value for missing heights in children, which assumes no growth, thus underestimating the eGFR for that time point. However, the regression line was calculated using all available eGFR data, making this less of an issue. A higher initial eGFR may produce a steeper regression slope and possibly explain these observed associations. The 7-year median followup time did not allow analysis of the impact of transition age for different age groups at transplant. We did not conduct a mediation analysis; hence for those variables with potential mediators, total effects only were measured. Our eGFR decline model only explained $5 \%$ of the observed variance which may be the result of linear 
eGFR modelling and/or unmeasured variables. We found an interaction between ethnicity and initial eGFR, where Black ethnicity and better initial function was associated with more rapid rate of eGFR decline. This suggests that this group need careful planning, counselling and clinical support. More work is required to understand these results. We were unable to evaluate residual confounders, such as trends in care such as immunosuppression regimes, surgical advances and kidney allocation policy, although we found no time-period effects in multivariable analyses. We lacked data on cause of graft loss.

\section{Conclusions}

In conclusion, young adulthood is a key risk factor for transplant loss and eGFR decline for UK children and young adults. Risk associations common to graft loss and eGFR decline include female sex, Black ethnicity and glomerular diseases. A higher initial eGFR was associated with less risk of graft loss but faster rate of eGFR decline. It is anticipated that the findings from this study will support health professionals to accurately counsel young people about the life expectancy of their kidney transplant.

\section{Supplementary Information}

The online version contains supplementary material available at https://doi. org/10.1186/s12882-020-02156-2.

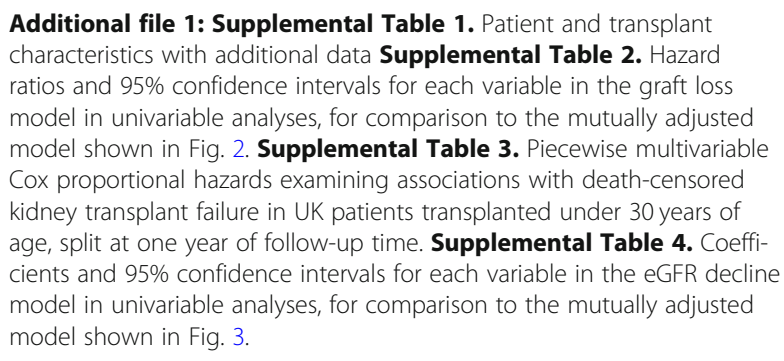

Additional file 1: Supplemental Table 1. Patient and transplant characteristics with additional data Supplemental Table 2. Hazard ratios and 95\% confidence intervals for each variable in the graft loss model in univariable analyses, for comparison to the mutually adjusted model shown in Fig. 2. Supplemental Table 3. Piecewise multivariable Cox proportional hazards examining associations with death-censored kidney transplant failure in UK patients transplanted under 30 years of age, split at one year of follow-up time. Supplemental Table 4. Coefficients and 95\% confidence intervals for each variable in the eGFR decline model in univariable analyses, for comparison to the mutually adjusted model shown in Fig. 3.

\section{Abbreviations}

Cl: Confidence interval; eGFR: Estimated glomerular filtration rate; ESKD: End stage kidney disease; HLA: Human leucocyte antigen; HR: Hazard ratio; IAPT: Improving Access to Psychological Therapies; IQR: Interquartile range; KRT: Kidney replacement therapy; NIHR: National Institute for Health Research; NHS: National Health Service; NHSBT: National Health Service Blood \& Transplant; NICE: National Institute for Health and Care Excellence; UKRR: United Kingdom Renal Registry; UKTR: United Kingdom Transplant Registry

\section{Acknowledgements}

We thank all the UK renal units for providing data to the UK Renal Registry and thank the Scottish Renal Registry for sharing the data they collect and validate in Scotland.

Any views or opinions expressed are solely those of the authors and do not necessarily represent those of the UK Renal Registry.

The authors are grateful to all the transplant centres in the UK who contributed data on which this article is based.

\section{Authors' contributions}

Defined using Contributor Roles Taxonomy (CRediT). AH: Conceptualization; Data curation; Formal Analysis; Funding acquisition; Investigation;
Methodology; Project administration; Software; Visualization; Writing original draft; Writing - review \& editing. LP: Conceptualization; Investigation; Methodology; Project administration; Writing - original draft; Writing review \& editing. AC: Conceptualization; Data curation; Investigation; Methodology; Project administration; Resources; Software; Writing - original draft; Writing - review \& editing. MS: Conceptualization; Investigation; Methodology; Project administration; Supervision; Writing - original draft; Writing - review \& editing. The author(s) read and approved the final manuscript.

\section{Funding}

This study received no direct funding.

$\mathrm{AH}$ acknowledges financial support via a National Institute for Health Research (NIHR) Clinical Lectureship. Through the Renal Association 2019 AEG Raine Award, AH received a full article-processing charge waiver to publish one article in BMC Nephrology.

MDS acknowledges financial support from the Department of Health via the NIHR comprehensive Biomedical Research Centre and Clinical Research Facilities awards to Guy's and St Thomas' NHS Foundation Trust in partnership with King's College London and King's College Hospital NHS Foundation Trust.

\section{Availability of data and materials}

The data that support the findings of this study are available from the UK Renal Registry and UK Transplant Registry but restrictions apply to the availability of these data, which were used under license for the current study, and so are not publicly available.

Details of the application process for access to individual level (anonymised) UK Renal Registry data for research and non-research purposes are available from https://renal.org/audit-research/how-access-data/ukrr-data. Details of how to access UK Transplant Registry data are available from https://www. odt.nhs.uk/statistics-and-reports/access-data/.

\section{Ethics approval and consent to participate}

Since the UK Renal Registry has been granted a section 251 exemption by the Health Research Authority, which allows the registration of identifiable patient information from kidney units without first asking individual patient consent, formal research ethics committee approval was not required. We applied for data using the formal data application processes of the UK Renal Registry and UK Transplant Registry. The UK Renal Registry data application was approved by the Medical Director and Chair of the Research Methods Study Group. The UK Transplant Registry data application was approved by the Kidney Advisory Group.

\section{Consent for publication}

Not applicable.

\section{Competing interests}

The authors declare that they have no competing interests.

\section{Author details}

${ }^{1}$ Population Health Sciences, University of Bristol, G.04, Canynge Hall, 39 Whatley Road, Bristol BS8 2PS, UK. ${ }^{2}$ UK Renal Registry, Bristol, UK. ${ }^{3}$ Evelina London Children's Hospital, London, UK. ${ }^{4}$ Kings College London, London, UK.

Received: 12 June 2020 Accepted: 8 November 2020

Published online: 18 November 2020

\section{References}

1. Goldstein SL, Graham N, Burwinkle T, Warady B, Farrah R, Varni JW. Healthrelated quality of life in pediatric patients with ESRD. Pediatr Nephrol. 2006; 21(6):846-50.

2. Howard K, Salkeld G, White S, McDonald S, Chadban S, Craig JC, Cass A. The cost-effectiveness of increasing kidney transplantation and home-based dialysis. Nephrology (Carlton). 2009;14(1):123-32.

3. Foster BJ, Dahhou M, Zhang X, Platt RW, Samuel SM, Hanley JA. Association between age and graft failure rates in young kidney transplant recipients. Transplantation. 2011;92(11):1237-43.

4. Samuel SM, Nettel-Aguirre A, Hemmelgarn BR, Tonelli MA, Soo A, Clark C, Alexander RT, Foster BJ. Pediatric renal outcomes Canada G: graft failure 
and adaptation period to adult healthcare centers in pediatric renal transplant patients. Transplantation. 2011;91(12):1380-5.

5. Van Arendonk KJ, James NT, Boyarsky BJ, Garonzik-Wang JM, Orandi BJ, Magee JC, Smith JM, Colombani PM, Segev DL. Age at graft loss after pediatric kidney transplantation: exploring the high-risk age window. Clin J Am Soc Nephrol. 2013;8(6):1019-26.

6. Kabore R, Couchoud C, Macher MA, Salomon R, Ranchin B, Lahoche A, Roussey-Kesler G, Garaix F, Decramer S, Pietrement C, et al. Age-dependent risk of graft failure in young kidney transplant recipients. Transplantation. 2017;101(6):1327-35

7. Ritchie AG, Clayton PA, McDonald SP, Kennedy SE. Age-specific risk of renal graft loss from late acute rejection or non-compliance in the adolescent and young adult period. Nephrology (Carlton). 2018;23(6):585-91.

8. Blakemore S-J. Inventing ourselves: the secret life of the teenage brain: Hachette UK; 2018

9. Johnson RJ, Armstrong S, Belger MA, Fuggle SV, Martin S, Middleton D, Ray TC, Rigden SP, Verrier-Jones K, Morris PJ, et al. The outcome of pediatric cadaveric renal transplantation in the UK and Eire. Pediatr Transplant. 2002; 6(5):367-77.

10. Rees L, Shroff R, Hutchinson C, Fernando ON, Trompeter RS. Long-term outcome of paediatric renal transplantation: follow-up of 300 children from 1973 to 2000. Nephron Clin Pract. 2007;105(2):c68-76.

11. Marlais M, Hudson A, Pankhurst L, Fuggle SV, Marks SD. Living donation has a greater impact on renal allograft survival than HLA matching in pediatric renal transplant recipients. Transplantation. 2016;100(12):2717-22.

12. Opelz G, Dohler B, Middleton D, Susal C, Report ACTS. HLA matching in pediatric kidney transplantation: HLA poorly matched living donor transplants versus HLA well-matched deceased donor transplants. Transplantation. 2017;101(11):2789-92.

13. Pankhurst T, Evison F, Mytton J, Williamson S, Kerecuk L, Lipkin G. Young adults have worse kidney transplant outcomes than other age groups. Nephrol Dial Transplant. 2020;35(6):1043-51.

14. Hamilton AJ, Braddon F, Casula A, Lewis M, Mallett T, Marks SD, Shenoy M, Sinha MD, Tse Y, Maxwell H. UK renal registry 19th annual Report: chapter 4 demography of the UK Paediatric renal replacement therapy population in 2015. Nephron. 2017;137(Suppl 1):103-16.

15. Plumb L, Wong E, Casula A, Braddon F, Lewis M, Marks SD, Shenoy M, Sinha MD, Maxwell H. Chapter 4 demography of the UK Paediatric renal replacement therapy population in 2016. Nephron. 2018;139(Suppl 1):10516.

16. SJ MN, Ford D, Evans K, Medcalf JF. Chapter 2 UK Renal Replacement Therapy Adult Prevalence in 2016: National and Centre-specific analyses. Nephron. 2018;139(Suppl 1):47-74.

17. Johnson RJ, Fuggle SV, Mumford L, Bradley JA, Forsythe $J$, Rudge CJ. Kidney advisory group of NHS Blood \& Transplant: a new UK 2006 National Kidney Allocation Scheme for deceased heart-beating donor kidneys. Transplantation. 2010;89(4):387-94.

18. Noordzij M, Leffondre K, van Stralen KJ, Zoccali C, Dekker FW, Jager KJ. When do we need competing risks methods for survival analysis in nephrology? Nephrol Dial Transplant. 2013;28(11):2670-7.

19. Cleves M. Analysis of multiple failure-time data with Stata. Stata Tech Bull. 2000;9(49);30-39.

20. Efron B. The efficiency of Cox's likelihood function for censored data. J Am Stat Assoc. 1977;72(359):557-65

21. Zoppini G, Targher G, Chonchol M, Ortalda V, Negri C, Stoico V, Bonora E. Predictors of estimated GFR decline in patients with type 2 diabetes and preserved kidney function. Clin J Am Soc Nephrol. 2012;7(3):401-8.

22. Turin $T C$, Coresh J, Tonelli M, Stevens PE, de Jong PE, Farmer CK, Matsushita K, Hemmelgarn BR. Change in the estimated glomerular filtration rate over time and risk of all-cause mortality. Kidney Int. 2013; 83(4):684-91.

23. Pyart R, Evans KM, Steenkamp R, Casula A, Wong E, Magadi W, Medcalf J. The 21st UK renal registry annual Report: a summary of analyses of adult data in 2017. Nephron. 2020;144(2):59-66.

24. Schwartz GJ, Munoz A, Schneider MF, Mak RH, Kaskel F, Warady BA, Furth SL. New equations to estimate GFR in children with CKD. J Am Soc Nephrol. 2009;20(3):629-37

25. Levey AS, Bosch JP, Lewis JB, Greene T, Rogers N, Roth D. A more accurate method to estimate glomerular filtration rate from serum creatinine: a new prediction equation. Modification of diet in renal disease study group. Ann Intern Med. 1999;130(6):461-70.
26. Ng DK, Schwartz GJ, Schneider MF, Furth SL, Warady BA. Combination of pediatric and adult formulas yield valid glomerular filtration rate estimates in young adults with a history of pediatric chronic kidney disease. Kidney Int. 2018:94(1):170-7.

27. Venkat-Raman G, Tomson CR, Gao Y, Cornet R, Stengel B, Gronhagen-Riska C, Reid C, Jacquelinet C, Schaeffner E, Boeschoten E, et al. New primary renal diagnosis codes for the ERA-EDTA. Nephrol Dial Transplant. 2012; 27(12):4414-9.

28. Hamilton AJ, Casula A, Ben-Shlomo Y, Caskey FJ, Inward CD. The clinical epidemiology of young adults starting renal replacement therapy in the UK: presentation, management and survival using 15 years of UK renal registry data. Nephrol Dial Transplant. 2018;33(2):356-64

29. Tools and calculators in relation to organ transplantation [https://www.odt. nhs.uk/transplantation/tools-policies-and-guidance/calculators/]

30. Tong A, Gill J, Budde K, Marson L, Reese PP, Rosenbloom D, Rostaing L, Wong G, Josephson MA, Pruett TL, et al. Toward establishing Core outcome domains for trials in kidney transplantation: Report of the standardized outcomes in nephrology-kidney transplantation consensus workshops. Transplantation. 2017:101(8):1887-96.

31. Hamilton AJ, Caskey FJ, Casula A, Ben-Shlomo Y, Inward CD. Psychosocial health and lifestyle behaviors in young adults receiving renal replacement therapy compared to the general population: findings from the SPEAK study. Am J Kidney Dis. 2019;73(2):194-205.

32. Hamilton AJ, Clissold RL, Inward CD, Caskey FJ, Ben-Shlomo Y. Sociodemographic, Psychologic health, and lifestyle outcomes in young adults on renal replacement therapy. Clin J Am Soc Nephrol. 2017;12(12): 1951-61.

33. Hamilton AJ, Caskey FJ, Casula A, Inward CD, Ben-Shlomo Y. Associations with wellbeing and medication adherence in young adults receiving kidney replacement therapy. Clin J Am Soc Nephrol. 2018;13(11):1669-79.

34. Bailey PK, Hamilton AJ, Clissold RL, Inward CD, Caskey FJ, Ben-Shlomo Y, Owen-Smith A. Young adults' perspectives on living with kidney failure: a systematic review and thematic synthesis of qualitative studies. BMJ Open. 2018:8(1):e019926.

35. Harden PN, Walsh G, Bandler N, Bradley S, Lonsdale D, Taylor J, Marks SD. Bridging the gap: an integrated paediatric to adult clinical service for young adults with kidney failure. BMJ. 2012;344:e3718.

36. Chrysochou C, Ritchie J, Gorton J, Lloyd-Williams K, Hobson L, Armstrong S. An innovative model for young adult renal care. Br J Renal Med. 2016;21(3): 60-3.

37. Seekles ML, Ormandy P, Coyne E. Mapping the UK renal psychosocial workforce: the first comprehensive workforce survey. BMC Nephrol. 2019; 20(1):100.

38. Hamilton A, Gair R, Elias R, Chrysochou C. Renal young adult transition services: a national survey. Br J Ren Med. 2017;22(2):36-8.

39. Bonthuis M, Cuperus L, Chesnaye NC, Akman S, Melgar AA, Baiko S, Bouts $\mathrm{AH}$, Boyer $\mathrm{O}$, Dimitrova $\mathrm{K}, \mathrm{Cd} \mathrm{C}$, et al. Results in the ESPN/ERA-EDTA registry suggest disparities in access to kidney transplantation but little variation in graft survival of children across Europe. Kidney Int. 2020;98(2):464-75.

40. Foster BJ, Dahhou M, Zhang X, Platt RW, Hanley JA. Relative importance of HLA mismatch and donor age to graft survival in young kidney transplant recipients. Transplantation. 2013;96(5):469-75.

41. Chesnaye NC, van Stralen KJ, Bonthuis M, Groothoff JW, Harambat J, Schaefer F, Canpolat N, Garnier A, Heaf J, de Jong H, et al. The association of donor and recipient age with graft survival in paediatric renal transplant recipients in a European Society for Paediatric Nephrology/European renal association-European Dialysis and transplantation association registry study. Nephrol Dial Transplant. 2017;32(11):1949-56.

42. Dharnidharka VR, Fiorina P, Harmon WE. Kidney transplantation in children. N Engl J Med. 2014;371(6):549-58.

43. Richardson C, Williams A, McCready J, Khalil K, Evison F, Sharif A. Clinic nonattendance is a risk factor for poor kidney transplant outcomes. Transplant Direct. 2018;4(11):e402.

44. Lenihan CR, O'Kelly P, Mohan P, Little D, Walshe JJ, Kieran NE, Conlon PJ. MDRD-estimated GFR at one year post-renal transplant is a predictor of long-term graft function. Ren Fail. 2008;30(4):345-52.

45. Lam NN, Tonelli M, Lentine KL, Hemmelgarn B, Ye F, Wen K, Klarenbach S. Albuminuria and posttransplant chronic kidney disease stage predict transplant outcomes. Kidney Int. 2017;92(2):470-8.

46. Lofaro D, Jager KJ, Abu-Hanna A, Groothoff JW, Arikoski P, Hoecker B, Roussey-Kesler G, Spasojevic B, Verrina E, Schaefer F, et al. Identification of 
subgroups by risk of graft failure after paediatric renal transplantation: application of survival tree models on the ESPN/ERA-EDTA registry. Nephrol Dial Transplant. 2016;31(2):317-24.

47. Kassakian CT, Ajmal S, Gohh RY, Morrissey PE, Bayliss GP.

Immunosuppression in the failing and failed transplant kidney: optimizing outcomes. Nephrol Dial Transplant. 2016;31(8):1261-9.

48. Andrews PA. Standards Committee of the British Transplantation Society: summary of the British Transplantation Society guidelines for Management of the Failing Kidney Transplant. Transplantation. 2014;98(11):1130-3.

49. Boucquemont J, Pai ALH, Dharnidharka VR, Hebert D, Zelikovsky N, Amaral S, Furth SL, Foster BJ. Association between day of the week and medication adherence among adolescent and young adult kidney transplant recipients. Am J Transplant. 2019;20(1):274-81.

50. Ganjali R, Khoshrounejad F, Mazaheri Habibi MR, Taherzadeh Z, Golmakani R, Mostafavi SM, Eslami S. Effect and features of information technologybased interventions on self-management in adolescent and young adult kidney transplant recipients: a systematic review. Adolesc Health Med Ther. 2019;10:173-90

51. National Institute for Clinical Excellence. Depression in adults with a chronic physical health problem: recognition and management. Clinical guideline [CG91]. United Kingdom: National Institute for Clinical Excellence; 2010.

52. National Collaborating Centre for Mental Health. The improving access to psychological therapies manual. UK: NCCMH; 2018.

53. Clark DM. Implementing NICE guidelines for the psychological treatment of depression and anxiety disorders: the IAPT experience. Int Rev Psychiatry. 2011;23(4):318-27.

54. Li L, Astor BC, Lewis J, Hu B, Appel LJ, Lipkowitz MS, Toto RD, Wang X, Wright JT Jr, Greene TH. Longitudinal progression trajectory of GFR among patients with CKD. Am J Kidney Dis. 2012;59(4):504-12.

\section{Publisher's Note}

Springer Nature remains neutral with regard to jurisdictional claims in published maps and institutional affiliations.

Ready to submit your research? Choose BMC and benefit from:

- fast, convenient online submission

- thorough peer review by experienced researchers in your field

- rapid publication on acceptance

- support for research data, including large and complex data types

- gold Open Access which fosters wider collaboration and increased citations

- maximum visibility for your research: over $100 \mathrm{M}$ website views per year

At $\mathrm{BMC}$, research is always in progress.

Learn more biomedcentral.com/submissions 